\title{
Early-Life Experience Decreases Drug-Induced Reinstatement of Morphine CPP in Adulthood via Microglial-Specific Epigenetic Programming of Anti-Inflammatory IL-10 Expression
}

\author{
Jaclyn M. Schwarz, ${ }^{1}$ Mark R. Hutchinson, ${ }^{2}$ and Staci D. Bilbo ${ }^{1}$ \\ ${ }^{1}$ Department of Psychology and Neuroscience, Duke University, Durham, North Carolina 27705, 2Discipline of Pharmacology and Discipline of Physiology, \\ School of Medical Sciences, University of Adelaide, Adelaide, South Australia, Australia 5005
}

\begin{abstract}
A critical component of drug addiction research involves identifying novel biological mechanisms and environmental predictors of risk or resilience to drug addiction and associated relapse. Increasing evidence suggests microglia and astrocytes can profoundly affect the physiological and addictive properties of drugs of abuse, including morphine. We report that glia within the rat nucleus accumbens (NAcc) respond to morphine with an increase in cytokine/chemokine expression, which predicts future reinstatement of morphine conditioned place preference (CPP) following a priming dose of morphine. This glial response to morphine is influenced by early-life experience. A neonatal handling paradigm that increases the quantity and quality of maternal care significantly increases baseline expression of the anti-inflammatory cytokine IL-10 within the NAcc, attenuates morphine-induced glial activation, and prevents the subsequent reinstatement of morphine CPP in adulthood. IL-10 expression within the NAcc and reinstatement of CPP are negatively correlated, suggesting a protective role for this specific cytokine against morphine-induced glial reactivity and drug-induced reinstatement of morphine CPP. Neonatal handling programs the expression of IL-10 within the NAcc early in development, and this is maintained into adulthood via decreased methylation of the $I L-10$ gene specifically within microglia. The effect of neonatal handling is mimicked by pharmacological modulation of glia in adulthood with ibudilast, which increases IL-10 expression, inhibits morphine-induced glial activation within the NAcc, and prevents reinstatement of morphine CPP. Taken together, we have identified a novel gene $\times$ early-life environment interaction on morphine-induced glial activation and a specific role for glial activation in drug-induced reinstatement of drug-seeking behavior.
\end{abstract}

\section{Introduction}

The neural pathways underlying reward induced by drugs of abuse are well known. Despite this, the mechanisms underlying an individual's risk or resilience to addiction and drug abuse potential remain poorly understood. Many factors affect an individual's risk of addiction, including genetic, environmental, and physiological factors. Of these factors, the early-life environment of an individual may be especially critical. Early-life stress in rodents can increase measures of self-administration and conditioned place preference (CPP) to drugs of abuse (Kosten et al.,

Received June 29, 2011; revised 0ct. 26, 2011; accepted 0ct. 26, 2011.

Author contributions: J.M.S., M.R.H., and S.D.B. designed research; J.M.S. performed research; J.M.S. analyzed data; J.M.S. and S.D.B. wrote the paper.

This work was supported by NIH Grants R01DA025978 and F32DA030136, and National Health and Medical Research Council CJ Martin Fellowship (ID 465423; 2007-2010) and an Australian Research Council Research Fellowship (DP110100297; 2011). We thank Paige W. Sholar, Dr. Herb E. Covington, Sonia M. Sabater, Ashwin Agarwal, Joel Colvill, and Dr. Andrew Somogyi for technical assistance and Dr. Susan H. Smith and Dr. Nicole C. Huff for comments on the manuscript.

The authors declare no competing financial interests.

Correspondence should be addressed to Dr. Jaclyn M. Schwarz, Duke University, 572 Research Drive, Box 91050, Durham, NC 27705, E-mail: jaclyn.schwarz@duke.edu

DOI:10.1523/JNEUROSCI.3297-11.2011

Copyright $\odot 2011$ the authors $\quad 0270-6474 / 11 / 3117835-13 \$ 15.00 / 0$
2000; Jaworski et al., 2005; Moffett et al., 2007; Michaels and Holtzman, 2008), although the effects of early-life stress are dependent upon the paradigm used and the behavioral endpoint measured (Lu et al., 2003). In contrast, neonatal handling paradigms that enhance maternal care reduce measures of reward/ dependency to drugs of abuse in adulthood (Jaworski et al., 2005; Moffett et al., 2007; Campbell and Spear, 1999; Sternberg and Ridgway, 2003). These examples of long-term "programming" in brain and behavior are often attributed to changes in stress responsiveness that in turn impact neural function. However, research from our laboratory provides evidence that early-life events can permanently alter immune function within the brain, which has long-term consequences for neural function and behavior. In particular, we have reported that neonatal handling significantly attenuates the long-term adverse consequences of a neonatal infection via a long-term decrease in glial cell reactivity within the brain (Bilbo et al., 2007).

Glia, including microglia and astrocytes, are the most abundant cell type in the brain and the primary immunocompetent cells of the CNS. Notably, glial cells are activated by drugs of abuse, and their activation and subsequent release of cytokines and chemokines can impact the physiological and addictive 
properties of drugs of abuse, including morphine. Morphineinduced proinflammatory glial activation alters neuronal excitability and synaptic connectivity, opposes morphine-induced analgesia, and increases tolerance, respiratory depression, withdrawal, and reward to morphine (Bland et al., 2010; Hutchinson et al., 2008a, 2009; Narita et al., 2008).

Given these collective findings, the hypotheses that guided the research presented are as follows: (1) drugs of abuse activate glia, thus increasing the likelihood of abuse, and (2) attenuating/preventing morphine-induced glial activation via early-life handling should therefore reduce abuse liability later in life. We present the following evidence in support of these hypotheses: (1) morphine activates glia within the nucleus accumbens (NAcc), inducing a rapid increase in cytokines and chemokines; (2) neonatal handling increases expression of the anti-inflammatory cytokine IL10, attenuates morphine-induced glial activation within the NAcc, and protects these rats from drug-induced reinstatement of morphine CPP; and (3) treatment of adult rats with a glial modulator, ibudilast, mimics neonatal handling by increasing IL-10 expression, blocking glial activation within the NAcc, and preventing reinstatement of CPP. Neonatal handling increases IL-10 expression postnatally, and this is maintained into adulthood via decreased methylation of the $I L-10$ gene specifically within microglia of the NAcc. Thus, these experiments have identified a gene $X$ early-life environment interaction on glial function within the NAcc, which predicts risk versus resilience for relapse liability in a model of addiction.

\section{Materials and Methods}

\section{Subjects}

Adult male and female Sprague Dawley rats (55-65 d) were obtained from Harlan and housed in polypropylene cages with ad libitum access to food and water. The colony was maintained at $22^{\circ} \mathrm{C}$ on a $12: 12 \mathrm{~h}$ lightdark cycle (lights on at 7:00 A.M. Eastern Standard Time). Males and females were paired into breeders. Female breeders were examined daily for confirmation of pregnancy, and male breeders were removed from cages before the day of birth [postnatal day $(\mathrm{P}) 0$ ]. Litters were culled on $\mathrm{P} 2$ to a maximum of 10 pups/litter, retaining two females and as many male pups as possible.

\section{Drugs}

Morphine sulfate and naloxone $\mathrm{HCl}$ were obtained from the National Institute of Drug Abuse Drug Inventory Supply (Rockville, MD). Ibudilast was obtained from Sigma-Aldrich, catalog no. IO157 and dissolved in a 35\% polyethylene glycol/ $65 \%$ saline solution. Morphine sulfate and naloxone $\mathrm{HCl}$ were prepared and are reported as free base concentrations.

\section{Neonatal handling}

Half of the litters were assigned to be handled daily (Bilbo et al., 2007; Levine, 1967) or to remain undisturbed as nonhandled controls in home cages. Handling occurred daily between 2:00 and 4:00 P.M. from P2 to P20. Dams were removed from the home cage and placed into separate, clean polycarbonate cages. Pups were removed together from the home cage and placed into a separate cage with bedding. After $15 \mathrm{~min}$, pups were returned to the home cage followed by the dams. Male pups were weaned on P21 and housed in sibling pairs. A maximum of two to three pups from a litter were assigned to a single experimental group, except in quantitative real-time reverse-transcription PCR (qRT-PCR) experiments for which each animal came from a different litter to control for possible litter effects.

\section{Treatment and tissue collection}

At P60, handled and nonhandled control male rats were injected with either saline or morphine $(4 \mathrm{mg} / \mathrm{kg})$ subcutaneously at a volume of 1 $\mathrm{ml} / \mathrm{kg}$. Ibudilast was administered $30 \mathrm{~min}$ before morphine administration at $7.5 \mathrm{mg} / \mathrm{kg}$ intraperitoneally in vehicle at $1 \mathrm{ml} / \mathrm{kg}$. Fifteen minutes after morphine or saline administration, rats were deeply anesthetized with a ketamine/xylazine cocktail and transcardially perfused with icecold saline for 2 min to clear brain vessels of blood and peripheral cells, thereby limiting contamination by peripheral immune factors. A portion of spleen was collected, brains were extracted, and the NAcc (core and shell, bregma +2.20 to +0.70 ) and hippocampus were rapidly microdissected and snap frozen via immersion in isopentane and stored at $-80^{\circ} \mathrm{C}$ until further processing.

\section{Corticosterone assessment}

Total serum corticosterone concentrations were assessed using a colorimetric enzyme immunoassay (EIA) kit from Assay Designs as described previously (Bilbo et al., 2007). The assay was run according to the manufacturer's instructions, except that serum $(5 \mu \mathrm{l})$ was diluted 1:50 in $0.05 \%$ steroid displacement-modified assay buffer. The detection limit of the assay is $27 \mathrm{pg} / \mathrm{ml}$. Blood was centrifuged at $10,000 \mathrm{rpm}$ at $4^{\circ} \mathrm{C}$ for 10 min. Supernatant (serum) was collected and stored at $-20^{\circ} \mathrm{C}$ until the assay.

\section{Serum IL-10 assessment}

Total serum IL-10 concentrations were assessed using a colorimetric EIA kit from R\&D Systems according to the manufacturer's instructions, except that serum was diluted 1:6 in assay buffer. The limit of detection for this assay is $10 \mathrm{pg} / \mathrm{ml}$. Blood was centrifuged at $10,000 \mathrm{rpm}$ at $4^{\circ} \mathrm{C}$ for $10 \mathrm{~min}$. Supernatant (serum) was collected and stored at $-20^{\circ} \mathrm{C}$ until the assay.

\section{Quantitative real-time PCR}

RNA was isolated from spleen, NAcc, or hippocampus using the TRIzol method and DNase treated. Complimentary DNA (cDNA) was synthesized from $500 \mathrm{ng}$ of isolated RNA using the RT ${ }^{2}$ First Strand Kit (catalog no C-03; SABiosciences/Qiagen). Gene expression was measured using quantitative real-time PCR with primers designed to measure 85 rat inflammatory cytokines, chemokines, and receptors (catalog no. PARN011; SABiosciences/Qiagen) or primers listed below using the $\mathrm{RT}^{2}$ SYBR Green qPCR Master Mix (Cat. No PA-010; SABiosciences/Qiagen following the manufacturer's protocol.

\section{$q R T-P C R$ analysis}

Threshold amplification cycle number $\left(\mathrm{C}_{\mathrm{t}}\right)$ was determined for each reaction within the linear phase of the amplification plot, and relative gene expression was determined using the $2^{-\Delta \Delta C_{t}}$ method. Relative gene expression across groups was compared using a two-way ANOVA with early-life experience (handled or nonhandled control) and adult treatment (morphine or saline) as factors, or using a one-way ANOVA for the effects of glial modulation in nonhandled control rats. Genes that had a significant interaction of early-life experience and morphine treatment with $p \leq 0.005$ were pursued in subsequent experiments and presented. Significant interactions using a two-way ANOVA were followed up with the Holm-Sidak post hoc test, with $p<0.05$, to determine potential group differences. Significant overall effects using one-way ANOVA were followed up with the Tukey's post hoc test, with $p<0.05$.

\section{Conditioned place preference}

An unbiased conditioned place preference or CPP paradigm was used for these experiments within a two-chamber shuttle box that is divided into two equal-sized compartments. One side of the box was white with a grid floor and the other side of the box was black with a rod floor (catalog no MED-CPP2-RSAT; Med Associates). The test box was dimly lit and slightly brighter on the white side to eliminate the natural bias of the rats for the grid floor. Activity was measured with automated data collection using photo beam strips and a computer interface with Med-PC IV software. On day 1 , four groups of rats ( $n=12$ /group) were placed into the chamber, alternating the side into which the animal was introduced, and time spent in each side of the box was measured for $20 \mathrm{~min}$ (pre-test). One rat showed a strong preference for one side of the box on day 1 [the rat spent more than two-thirds of the total time $(800 \mathrm{~s})$ in a particular side of the box] and was eliminated from the experiments and replaced with another animal. On days 2 and 3, animals had two conditioning sessions: one in the A.M. between 8:00 and 12:00 and one in the P.M. between 1:00 and 5:00. Rats were randomly assigned to be conditioned to morphine in 
either the white or the black box during either the A.M. or P.M., counterbalancing this parameter across treatment groups using an "unbiased assignment procedure" (Cunningham et al., 2006). During the conditioning sessions, rats were injected alternately with either morphine (4 $\mathrm{mg} / \mathrm{kg})$ or saline $(1 \mathrm{ml} / \mathrm{kg})$ and placed into one side of the conditioning chamber with the guillotine door shut for $45 \mathrm{~min}$. The order of administration was randomized across treatment groups. Thirty minutes before the conditioning sessions, animals were treated with either ibudilast $(7.5 \mathrm{mg} / \mathrm{kg})$ or the vehicle. On day 4 , testing occurred between 2:00 and 4:00 P.M. Rats were placed into the chamber, and the time spent in each side of the box was measured for $20 \mathrm{~min}$ (post-test). The CPP score was determined by subtracting the time spent in the morphine-paired box during the post-test from the time spent in the morphine-paired box during the pre-test.

\section{Extinction}

Rats were placed into the CPP chamber with the guillotine door open for 5 min sessions three times per week. After three 5 min sessions each week, the rats received an extinction test the next day, which consisted of a 20 min session with the guillotine door open. Time spent in the morphinepaired box during the pre-test was subtracted from the time spent in the morphine-paired box during each extinction test.

\section{Hot plate analgesia test}

Animals were briefly habituated to the hot plate (Columbus Instruments for $1 \mathrm{~min}$, twice, for two days with the plate off. The baseline latency to respond to the heat $\left(52.5^{\circ} \mathrm{C}\right)$ with a back paw-lick response or jump attempt was measured in handled and nonhandled control rats two times, $30 \mathrm{~min}$ apart from each other. After baseline pain responses are obtained, animals were injected with $4 \mathrm{mg} / \mathrm{kg}$ morphine (subcutaneously) at a volume of $1 \mathrm{ml} / \mathrm{kg}$. The latency to respond to the pain was measured at 20, 40, 60, 90, and 120 min after morphine administration. No animals tested reached the maximum response latency of $60 \mathrm{~s}$, which would have been used to avoid tissue damage. The maximal percentage effectiveness (\%MPE) was determined by subtracting the average baseline response latency (obtained from two trials in the absence of morphine) from the response latency obtained in the presence of morphine and taking that as a percentage of the maximal response latency.

\section{Pharmacokinetic analysis of morphine}

Tissue morphine concentrations were quantified using a modified liquid chromatography/mass spectrometry (LC/MS) detection method based on the work of Somogyi et al. (2008). The MS detector (Shimadzu LCMS2010A) detected the compounds of interest using single ion monitoring mode at $\mathrm{m} / \mathrm{z}$ ratios of morphine: (286.05) and $\mathrm{d} 3$-morphine (289.05). Detection parameters of the system were as follows: nebulizing gas flow, $4 \mathrm{~L} / \mathrm{min}$; CDL temperature, $250^{\circ} \mathrm{C}$; block temperature, $300^{\circ} \mathrm{C}$; probe voltage, $3 \mathrm{kV}$; detector, $1.6 \mathrm{kV}$; CDL, $175 \mathrm{~V}$; and Q array, $30 \mathrm{~V} / \mathrm{RF} 150$. Serum samples $(100 \mu \mathrm{l})$ aliquots were added into $10 \mathrm{ml}$ tapered tubes, followed by $100 \mu \mathrm{l}$ of water and $100 \mu \mathrm{l}$ of d3-morphine internal standard (20 ng/ml). Seven hundred microliters of glycine extraction buffer was added and the samples were vortexed for $5 \mathrm{~s}$, followed by the addition of $5 \mathrm{ml}$ of hexane:ether (70:30), and rotary mixed for $20 \mathrm{~min}$. Samples were then centrifuged at $2250 \times g$ for $10 \mathrm{~min}$, shaken vigorously to form a clean interface, and centrifuged again at $2250 \times g$ for a further $10 \mathrm{~min}$. The organic fraction $(\sim 4800 \mu \mathrm{l})$ was then transferred into a separate 10 $\mathrm{ml}$ tapered bottom tube preloaded with $200 \mu \mathrm{l}$ of $\mathrm{HCl}(0.1 \mathrm{M})$ and vortexed for $60 \mathrm{~s}$, followed by centrifugation at $2250 \times \mathrm{g}$ for $10 \mathrm{~min}$. Finally, the organic fraction was aspirated and $120 \mu \mathrm{l}$ of the remaining aqueous acid fraction was transferred in injection vials where $100 \mu$ l of the sample was injected onto a $150 \times 2.00 \mathrm{~mm} 5 \mathrm{u} \mathrm{C18}$ column at a $0.2 \mathrm{ml} / \mathrm{min}$ flow rate. Calibration standards range from $1 \mathrm{ng} / \mathrm{ml}$ to $150 \mathrm{ng} / \mathrm{ml}$, and samples above this are diluted with blank serum with the addition of the internal standard. High $(75 \mathrm{ng} / \mathrm{ml})$, medium $(20 \mathrm{ng} / \mathrm{ml})$, and low $(3.75 \mathrm{ng} / \mathrm{ml})$ quality control samples were assayed with each assay and are expected to be within $10 \%$ of the nominal concentrations. The limit of quantification is $3.75 \mathrm{ng} / \mathrm{ml}$.

\section{Cannulae implantation}

Chronic indwelling stainless steel bilateral guide cannulae (26 g; Plastics One) were implanted in the dorsal portion of the NAcc according to the following coordinates: anteroposterior, $+2.16 \mathrm{~mm}$; mediolateral, \pm 1.5 $\mathrm{mm}$; dorsoventral, $-5.75 \mathrm{~mm}$ (Paxinos and Watson, 2005). Cannulae were secured with dental cement (Bosworth Trim II) and a jeweler's screw implanted in the skull. Dummy cannulae ( $33 \mathrm{~g}, 1 \mathrm{~mm}$ projection, Plastics One) were placed in the guide cannulae to maintain patency. Rats were allowed to recover for $5 \mathrm{~d}$ before behavioral experiments.

\section{Microinjection procedure}

Rats were microinjected with either vehicle (4\% Captisol, CyDex Pharmaceuticals; in sterile PBS) or ibudilast in vehicle, depending on the experiment, while under light isoflurane anesthesia $1 \mathrm{~h}$ before morphine treatment using an internal infusion cannula $(33 \mathrm{~g}, 1 \mathrm{~mm}$ projection; Plastics One). The doses of ibudilast used for infusion ( 23 or $230 \mathrm{ng}$ ) were based on two experiments that treated glial cells (rodent or human) with $100 \mu \mathrm{M}$ ibudilast (23 ng in $1 \mu \mathrm{l}$ ) in culture (Suzumura et al., 1999; Kiebala and Maggirwar, 2011). These studies determined that $100 \mu \mathrm{M}$ ibudilast inhibits phosphodiesterase III $\sim 35-40 \%$, and thereby inhibits the synthesis of cytokines and chemokines from glial cells by $\sim 50-80 \%$, depending upon the protein of analysis. Thus we used two doses for our initial experiments based on these culture experiments, 23 and $230 \mathrm{ng}$, to establish a small dose-response curve to determine that $230 \mathrm{ng}$ of ibudilast significantly attenuates morphine-induced glial activation and has no demonstrable side effects. All injections into the NAcc were delivered using a microinjection syringe pump (Harvard Apparatus) in a volume of $1 \mu \mathrm{l}$ over $5 \mathrm{~min}$, after which the infusion cannulae were kept in the guide cannulae for an additional $5 \mathrm{~min}$. Before conditioning with saline, rats were placed under light isoflurane anesthesia and injection cannulae were placed in the guide cannulae, but no liquid was infused to avoid infusing too much liquid into the NAcc during one day. This procedure was repeated for both days of CPP conditioning.

\section{Histology}

Once all testing was completed, rats were anesthetized and transcardially perfused with $0.1 \mathrm{~m}$ PBS, followed by $4 \%$ paraformaldehyde solution. Brains were sectioned on a cryostat (Leica) along the coronal plane at a thickness of $50 \mu \mathrm{m}$ and were stained with cresyl violet (1\% solution). Infusion cannulae tip placement was located using light microscopy and was mapped onto a schematic diagram of the rat brain (Paxinos and Watson, 2005).

\section{Microglial isolations}

Microglia were isolated from NAcc tissue as previously reported (Frank et al., 2006). Briefly, dissociated tissue was resuspended in 70\% isotonic Percoll (GE Healthcare) layered with a 50\% isotonic Percoll and a final layer of $1 \times$ PBS. Following centrifugation, two distinct layers were visible. The lower layer between the $70 \%$ and $50 \%$ Percoll phases contained a highly enriched and quiescent population of microglia that were removed and washed with $1 \times$ PBS, and taken directly through DNA extraction and methylation-dependent immunoprecipitation (MeDIP).

\section{Methylation-dependent immunoprecipitation with quantitative real-time PCR}

NAcc microdissections or isolated microglia from NAcc were homogenized in lysis buffer (50 mM Tris $\mathrm{HCl}, \mathrm{pH}$ 7.5, $100 \mathrm{~mm}$ EDTA, $100 \mathrm{~mm}$ $\mathrm{NaCl}, 1 \% \mathrm{SDS}$ ), and DNA was precipitated using phenol:chloroform: isoamyl alcohol extraction. DNA was sheared to an average size of $400-$ 800 bp by sonication (confirmed by agarose gel). Two micrograms of DNA was immunoprecipitated (IP) with a ChIP-grade 5-methylcytosine antibody using the EpiQuick Methylated DNA Immunoprecipitation Kit (Epigentek), ethanol precipitated, and resuspended in $10 \mu \mathrm{l}$ of elution buffer similar to protocols reported by others (Miller et al., 2010). Two micrograms of DNA was diluted into $10 \mu$ l of elution buffer and set aside as input (IN) DNA. Negative controls contained normal mouse IgG. Quantitative real-time PCR analysis of $1 \mu \mathrm{l}$ of IN DNA or IP DNA was performed using primers designed for a $100 \mathrm{bp}$ region of the $\mathrm{CpG}$ Island of the IL-10 gene (confirmed using CpG Island Searcher, cpgislands.usc.edu/) or GAPDH. Threshold amplification cycle numbers obtained within the linear range were used to calculate MeDIP DNA quantities and input DNA quantities for each sample, assayed in duplicate and analyzed using the $2^{-\Delta \Delta C_{t}}$ method. Amplified products were further confirmed by 
electrophoresis on $1 \%$ agarose gel stained with ethidium bromide and visualized under UV light.

\section{Primer specifications}

$m R N A$ primers. Real-time quantitative PCR primers were obtained from SABiosciences/Qiagen from catalog no. PARN-011 and catalog no. QT00177618 (IL-10).

MeDIP primers. IL-10 DNA forward primer was AAGCAAGGCAGTGG AGCA, and IL-10 DNA reverse primer was GGTGGCTTTCTAACTGGCA. GAPDH forward primer was CTTCGCCTCTTTCAATGTGC, and GAPDH reverse primer was GGTCAGTAGACTCTTACAGC.

\section{Statistical analysis}

A two-way ANOVA (early-life experience $\times$ morphine treatment) or a one-way ANOVA (glial modulation in nonhandled control rats) was used to analyze quantitative real-time PCR data for each inflammatory gene. A two-tailed Student's $t$ test with $p<0.05$ was used to compare CPP data from handled and nonhandled control rats alone, as well as subsequent reinstatement data. A two-way ANOVA (early-life experience $\times$ glial modulation) was also used to analyze CPP data, as well as subsequent reinstatement data from the final experiment. Extinction data were analyzed using a two-way repeated-measures ANOVA, $p<0.05$. Significant interactions using a two-way ANOVA or repeated-measures ANOVA were followed up with the Holm-Sidak post hoc test, with $p<0.05$, to determine group differences. Significant overall effects using one-way ANOVA were followed up with the Tukey's post hoc test, with $p<0.05$, to determine group differences. IL-10 expression at P10 in brain or at P60 in spleen, corticosterone levels, and MeDIP data collected from handled and nonhandled control rats were analyzed using a two-tailed Student's $t$ test with $p<0.05$. All data in graphical form represent the mean \pm SEM.

\section{Results}

Morphine produces rapid glial activation within the NAcc that is significantly attenuated by neonatal handling

Very little is known about the glial response to morphine, particularly in brain regions underlying reward. To characterize this, we assessed expression levels of CD11b and glial fibrillary acidic protein (GFAP) mRNA, two well established markers of microglia and astrocyte activation, respectively, within the NAcc of nonhandled control rats following morphine $(4 \mathrm{mg} / \mathrm{kg})$ treatment. Morphine produced a rapid increase in CD11b and GFAP within 15 min following morphine exposure that returned to baseline within $60 \mathrm{~min}$ post-morphine administration (Fig. $1 \mathrm{~A}$; CD11b: $F_{(3,19)}=4.81, p=0.014$; GFAP: $F_{(3,19)}=9.07, p<$ 0.001). For comparison, we measured the expression levels of these genes within the hippocampus of the same animals and determined that morphine does not produce the same glial activation observed in the NAcc (Fig. $1 B$; CD11b: $F_{(3,19)}=1.38, p=$ 0.277; GFAP: $\left.F_{(3,19)}=2.62, p=0.080\right)$.

To further characterize the inflammatory factors produced within the NAcc following morphine administration and how they may be affected by neonatal handling, neonatally handled and nonhandled control rats were treated with saline or morphine and inflammatory gene expression was measured within the NAcc after 15 or $30 \mathrm{~min}$. At the $15 \mathrm{~min}$ time point, 11 genes showed a significant interaction of early-life experience and morphine treatment (Fig. $1 C$; two-way ANOVA interaction for earlylife experience $\times$ morphine treatment, $p \leq 0.005$ for all genes depicted). Ten genes were significantly upregulated and one gene, the neuronal cytokine CX3CL1 (fractalkine), was significantly downregulated within the NAcc following morphine treatment. Neonatal handling completely blocked the morphineinduced cytokine/chemokine response within the NAcc. Notably, the anti-inflammatory cytokine, IL-10, was significantly upregulated within the NAcc of handled rats at baseline when compared to nonhandled controls (two-way ANOVA, early-life experience $\times$ morphine treatment interaction: $F_{(1,11)}=14.700$; $p=0.005$; post hoc, $p=0.012$ ). At the $30 \mathrm{~min}$ time point, the cytokine/chemokine response was resolved (data not shown), indicating that the glial response to morphine within the NAcc is both robust and rapid.

\section{Neonatal handling does not affect baseline IL-10 mRNA expression within the peripheral immune system}

To assess the peripheral cytokine response to morphine in handled and nonhandled control rats, serum protein levels of the proinflammatory cytokine, IL- $1 \beta$, and the anti-inflammatory cytokine, IL-10, were measured at baseline and at $45 \mathrm{~min}$ following morphine administration in handled and nonhandled control rats. IL- $1 \beta$ and IL- 10 were undetectable at baseline in the serum of handled and nonhandled control rats. Following morphine treatment, IL- $1 \beta$ remained undetectable (data not shown); however, IL-10 levels were significantly elevated. Interestingly, this increase in serum IL-10 was significantly attenuated in handled rats compared to nonhandled control rats (Fig. $2 A ; \mathrm{t}_{9}=-2.69$, $p=0.024)$. These data indicate that in contrast to the proinflammatory glial response within the CNS, morphine is immunosuppressive within the periphery, consistent with the large literature on this phenomenon (Budd, 2006; Sacerdote, 2008). Moreover, this suppression is modulated by early-life experience.

To explore the etiology of the group difference in serum IL-10 following morphine treatment, we measured IL-10 mRNA within the spleen to assess whether baseline expression of this gene was differentially regulated by neonatal handling as it was in the brain. While we had detected a 4 -fold increase in the baseline expression of IL-10 mRNA within the NAcc of handled rats; we found no such group difference within the spleen (Fig. $2 B ; t_{18}=$ $-1.05, p=0.307$ ), consistent with the lack of protein difference seen in the serum of handled and nonhandled control data. Together, these data indicate that morphine is immunosuppressive within the periphery, but that neonatal handling does not program baseline IL-10 expression within the peripheral immune system as it does within the brain. Rather, we hypothesize that the difference in peripheral immunosuppression following morphine administration between handled and nonhandled control rats is driven by the differential glial response within the NAcc, as it has been reported that the NAcc is necessary for the peripheral immunosuppression induced by morphine (Saurer et al., 2008, 2009).

\section{Neonatal handling attenuates morphine CPP and blocks subsequent reinstatement of CPP following morphine reexposure}

Having determined that neonatal handling can significantly attenuate morphine-induced gilal activation within the NAcc in adulthood, we next sought to determine whether neonatal handling would also attenuate the rewarding effects of morphine and relapse liability in a model of addiction, conditioned place preference or CPP. Handled and nonhandled control rats were conditioned to morphine $(4 \mathrm{mg} / \mathrm{kg}$ ) for $2 \mathrm{~d}$ using an unbiased CPP paradigm. Handled and nonhandled control rats spent more time in the morphine-paired chamber than in the saline-paired chamber on the day of testing; however, neonatally handled rats spent significantly less time in the morphine-paired chamber than control rats (Fig. $3 A ; t_{16}=2.08 ; p<0.05$ ), indicating that neonatal handling decreased the rewarding effects of morphine in these rats.

Following morphine CPP, all rats began an extinction phase whereby they were placed into the CPP environment in the ab- 


\section{A CD11b in NAcc GFAP in NAcc}
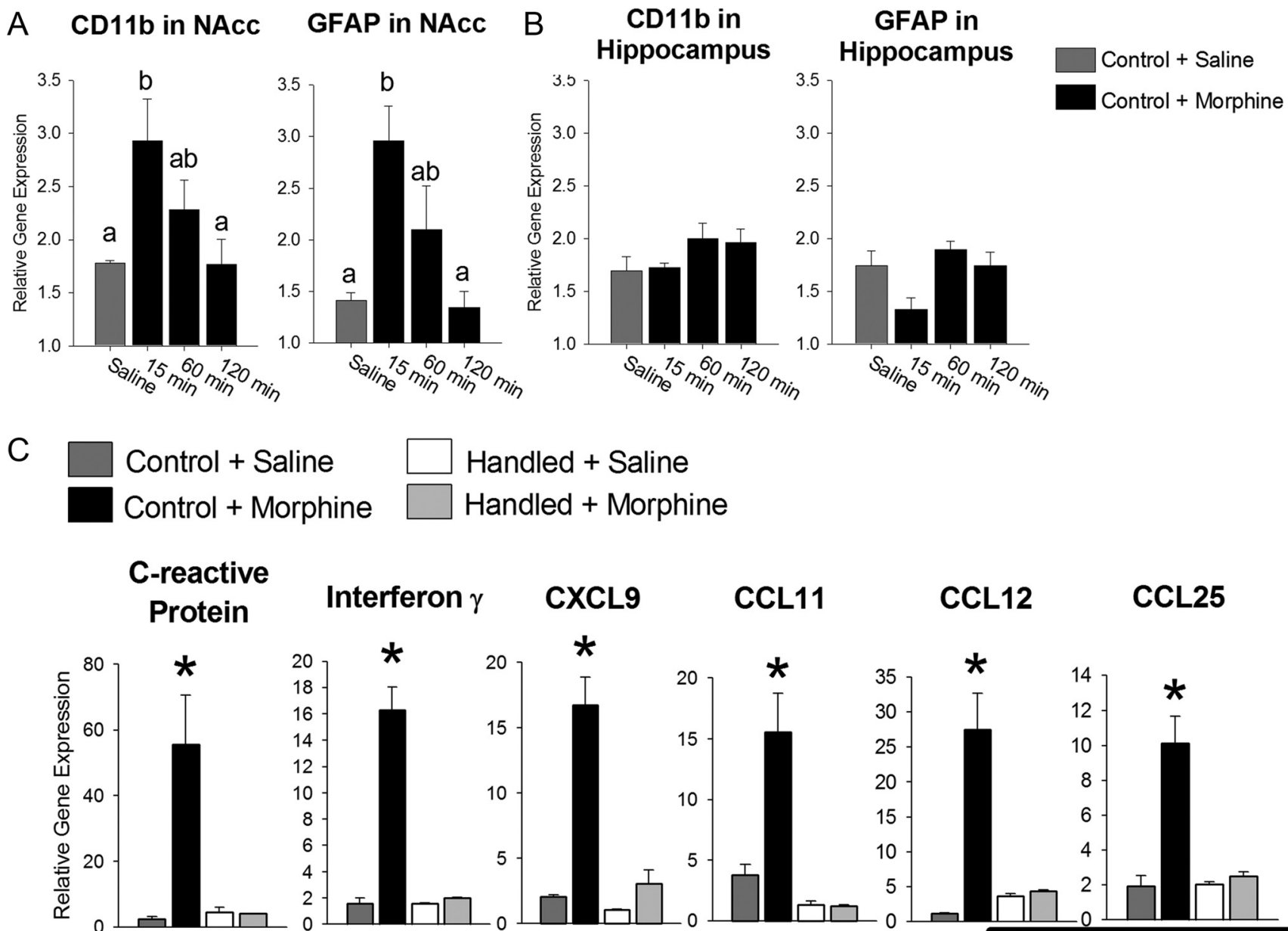

\section{CXCL9}

CCL11

CCL12

CCL25

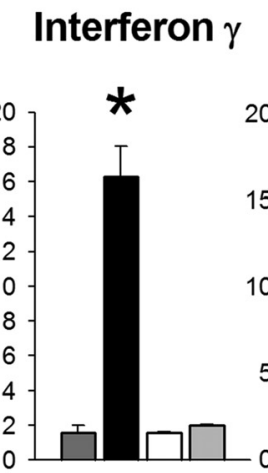

CCL4

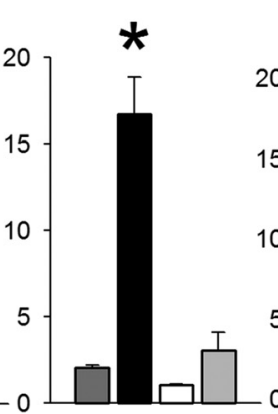

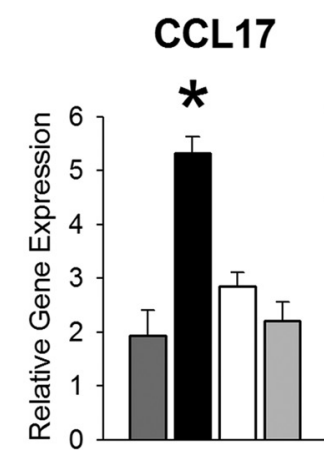

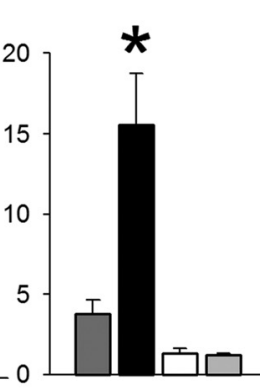

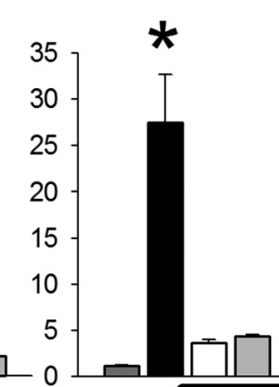

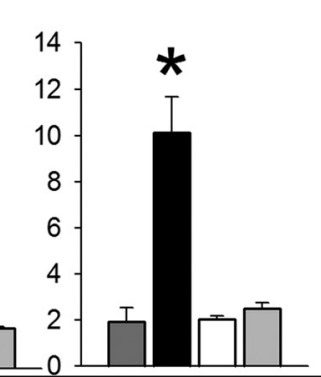

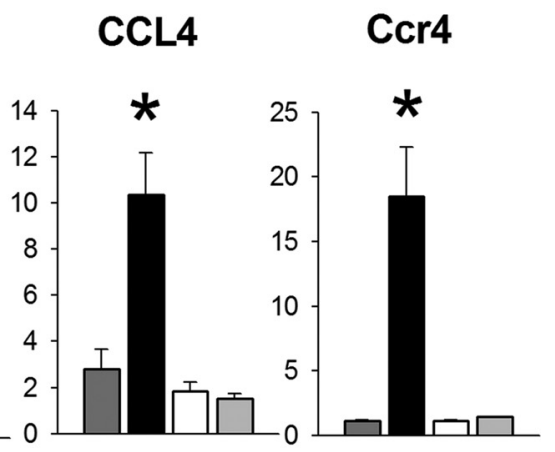
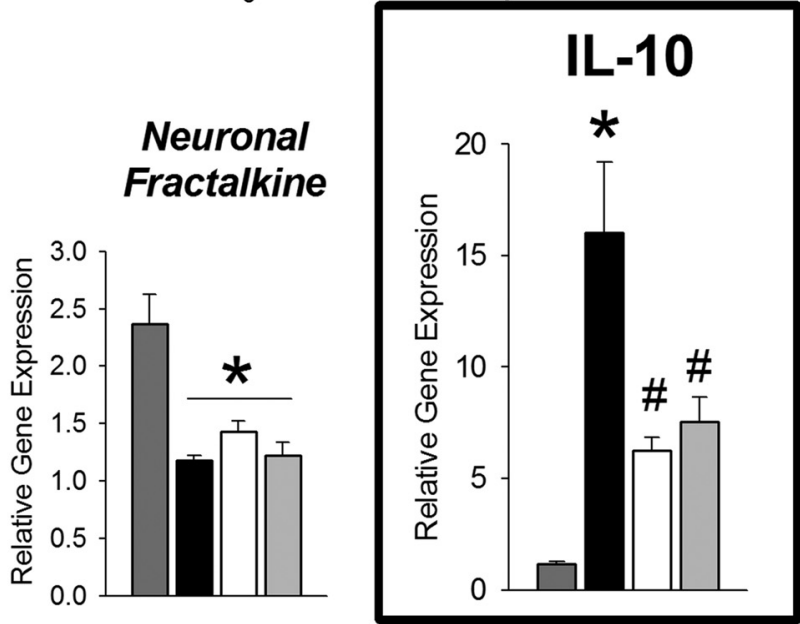

Figure 1. Morphine induces a rapid increase in the expression of glial activation markers within the NAcc, but not in the hippocampus, and a rapid and robust increase in cytokine and chemokine expression within the NAcc that is blocked by neonatal handling. Nonhandled control rats were treated with morphine (4 mg/kg) or saline and brains were collected 15, 60, or 120 min later. Analysis of CD11b, a marker of microglial activation, and GFAP, a marker of astrocyte activation, was performed on microdissections of the NAcc and the hippocampus of the same animals. A, CD11b and GFAP mRNA were significantly upregulated within the NAcc of control rats 15 min following morphine treatment ( $p<0.05$, when compared to saline-treated controls). Sixty minutes after morphine administration, CD11b and GFAP mRNA levels were declining such that they were no longer significantly different from either saline-treated controls or levels measured at 15 min. Different letters represent significant differences between groups. $\boldsymbol{B}$, Within the hippocampus, CD11b and GFAP mRNA were not significantly upregulated at any time point following morphine administration. C, Eleven genes showed a significant interaction following analysis with a two-way ANOVA. Morphine significantly increased the expression of 10 inflammatory genes and significantly decreased the expression of one neuronal cytokine (CX3CL1/fractalkine). Neonatal handling significantly blocked the morphine-induced changes in gene expression for all genes, except CX3CL1, which was significantly downregulated in handled rats when compared to nonhandled control rats treated with saline. IL-10 mRNA showed a significantly different pattern than other genes, as IL-10 mRNA was significantly upregulated in handled rats in the absence of morphine. Treatment of handled rats with morphine had no effect on IL-10 mRNA levels within the NAcc. (IL-10: ${ }^{*} p<0.05$ compared to all other groups; ${ }^{*} p<0.05$ compared to nonhandled control plud saline).

sence of morphine for a 5 min session 3 times per week and tested for morphine CPP (20 min test) once a week for 4 weeks. A repeated-measures ANOVA revealed a significant effect of test day $\left(F_{(4,64)}=3.25 ; p=0.017\right)$, such that the rats spent less time in the morphine-paired chamber during each test over the course of the month, and a significant interaction of test day $\times$ early-life experience $\left(F_{(4,64)}=2.90 ; p=0.028\right)$, as handled rats were faster to extinguish the preference for the morphine-paired chamber. 
By week 4, both treatment groups showed no preference for the morphine-paired chamber (Fig. $3 A$ ). At that point, rats were injected with saline before being placed in the CPP chambers, which produced no significant reinstatement of the CPP to morphine (Fig. 3B). The next day, both handled and nonhandled control rats were injected with morphine $(4 \mathrm{mg} / \mathrm{kg}$ ) before being placed in the CPP chambers, which produced a significant reinstatement of the morphine CPP only in nonhandled control rats (Fig. $3 B ; t_{16}=2.16 ; p=0.04$ ). Neonatally handled rats did not reinstate $\mathrm{CPP}$ behavior following reexposure to morphine.

\section{Attenuated morphine CPP in neonatally-handled rats is not attributed to differences in stress, morphine analgesia, or the pharmacokinetics of morphine}

Stress is an important factor that can influence drug addiction. Two well known, long-term effects of neonatal handling are decreased baseline serum corticosterone and decreased stress responsiveness (Levine, 1967; Meaney et al., 1991). To assess whether differences in corticosterone could explain our behavioral findings in the CPP paradigm, serum corticosterone levels were measured at several time points following morphine administration in a different set of rats and at two points during the CPP paradigm presented above. As previously reported (Bilbo et al., 2007; Meaney et al., 1991), baseline serum corticosterone levels were significantly decreased in handled when compared to nonhandled controls (Fig. $3 C ; t_{10}=-2.52, p=$ 0.031 ), yet no significant differences in the serum corticosterone levels were measured at any time point following morphine administration alone (25 $\mathrm{min}: t_{4}=-0.46, p=$ 0.669; 60 min: $t_{10}=0.46, p=0.655 ; 120$ min: $\left.t_{4}=0.11, p=0.917\right)$. Serum corticosterone levels were also not significantly different immediately following the first morphine conditioning session of CPP $\left(t_{15}=-0.67, p=0.513\right)$ or at the time of CPP testing (Fig. $3 D ; t_{16}=-1.53, p=$ 0.145 ), and neither measure correlates with CPP scores from the same animals (at conditioning: $R^{2}=0.11, \mathrm{t}_{15}=1.41, p=0.178$; at CPP testing: $R^{2}=0.11, t_{16}=-1.44, p=$ 0.177 ), suggesting that serum corticosterone did not significantly influence the differential rewarding effects of morphine observed in handled and nonhandled control rats.

In separate cohorts of handled and nonhandled control rats, morphine-induced analgesia and morphine pharmacokinetics were measured to determine whether these factors were different between the groups, as these factors could reflect broader differences in the glial response within the brain and influence subsequent experiments measuring reward. Morphine $(4 \mathrm{mg} / \mathrm{kg})$ produced significant analgesia $20 \mathrm{~min}\left(F_{(1,19)}=\right.$ $16.24 ; p=0.007), 40 \mathrm{~min}\left(F_{(1,19)}=17.7 ; p=0.005\right)$, and $60 \mathrm{~min}$ $\left.\left(F_{(1,19)}\right)=13.68 ; p=0.001\right)$ postmorphine administration quantified by a hot plate test; importantly there was no significant interaction of neonatal condition on morphine analgesia (Fig. $4 A$ ). Serum morphine concentrations were measured at 25, 60, and $120 \mathrm{~min}$ following a subcutaneous dose of morphine (4 mg/ $\mathrm{kg}$ ) in handled and nonhandled control rats. There was a significant main effect of time $\left(F_{(2,19)}=114.4 ; p<0.001\right)$, such that as expected serum morphine levels decreased with time. There was

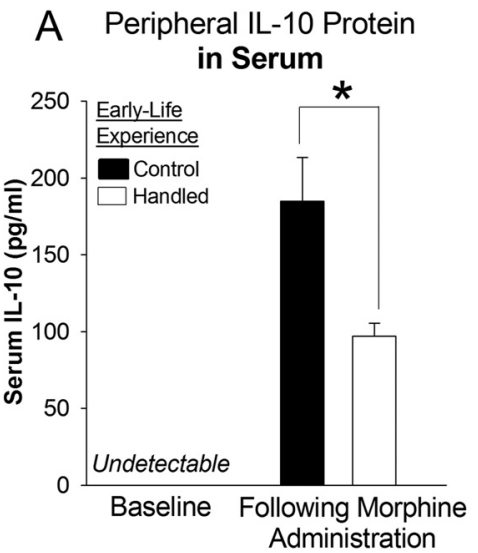

\section{B Baseline IL-10 mRNA in Spleen}

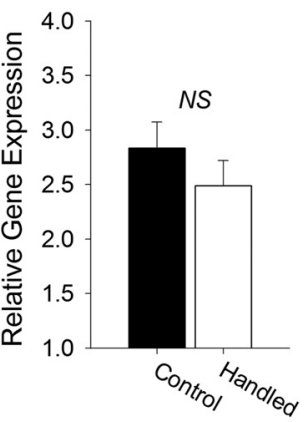

Early-Life Experience

Figure 2. Neonatal handling attenuates the peripheral immunosuppressive response to morphine, yet has no effect on baseline IL-10 expression within the peripheral immune system. $A$, Peripheral IL-10 protein was measured in the serum using an ELISA at baseline or $45 \mathrm{~min}$ following morphine administration in handled and nonhandled control rats. Baseline levels of IL-10 were undetectable in serum ( $n=4$ /group). Forty-five minutes following morphine administration, IL-10 levels were elevated; however, neonatal handling significantly decreased $\left({ }^{*} p<0.05\right)$ IL-10 levels within the serum following morphine administration when compared to nonhandled control rats ( $n=5 /$ group). $B$, Baseline IL-10 mRNA within the spleen was measured from handled and nonhandled control rats at $P 60$. No significant differences were detected ( $n=10$ group).
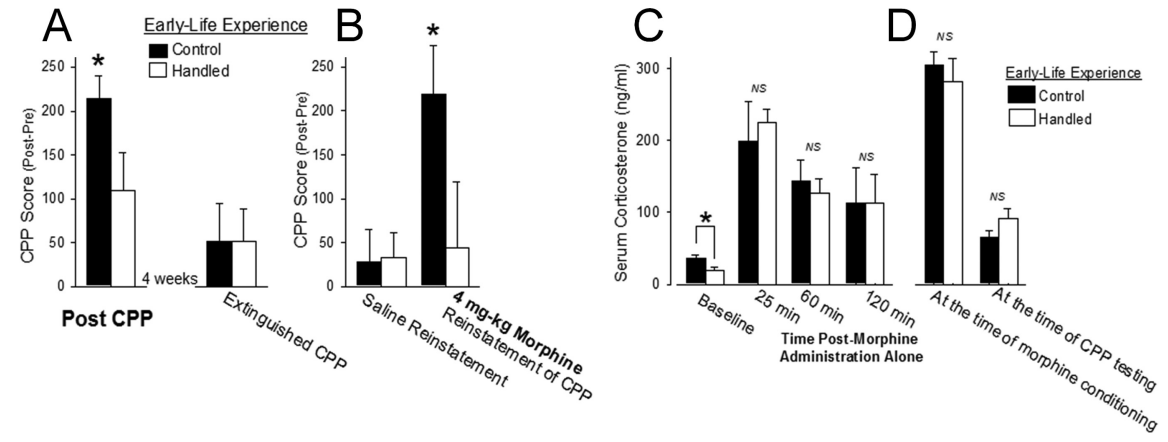

Figure 3. Neonatal handling significantly attenuates (PP to morphine $(4 \mathrm{mg} / \mathrm{kg})$ and blocks the reinstatement of CPP following reexposure to morphine, yet it does not affect serum corticosterone following morphine administration or during morphine CPP. $A$, Neonatal handling significantly decreased morphine preference when compared to nonhandled control rats. CPP score represents the time spent in the morphine-paired chamber post-CPP minus the time spent in the morphine-paired chamber pre-CPP ( $n=9 /$ group). Following morphine CPP, all rats went through an extinction phase and, after 4 weeks, both handled and nonhandled control rats showed a significant decrease in the amount of time spent in the morphine-paired chamber. $\boldsymbol{B}$, Injection with saline did not elicit reinstatement of $C P P$ behavior; however, injection with morphine ( $4 \mathrm{mg} / \mathrm{kg}$ ) reinstated morphine (PP behavior only in nonhandled control rats $\left({ }^{*} p<0.05 ; n=9 /\right.$ group). C, Baseline serum corticosterone levels were significantly increased in adult nonhandled control rats $(n=6)$ when compared to adult neonatally handed rats $\left(n=6 ;{ }^{*} p<0.05\right)$; however, serum corticosterone levels were not significantly different between the two groups at 25,60 , or $120 \mathrm{~min}$ after morphine $(4 \mathrm{mg} / \mathrm{kg}$ ) administration. $\boldsymbol{D}$, Using the rats from Figure $3, \boldsymbol{A}$ and $\boldsymbol{B}$ (handled: $n=8 /$ group -1 outlier nonhandled control: $n=9 /$ group), serum was collected immediately after the first morphine conditioning session of (PP or immediately following the CPP test and no significant differences in serum corticosterone were measured at either instance, indicating that this factor may not affect differences in morphine CPP between these groups. no main effect neonatal condition $\left(F_{(2,19)}=0.1 ; p=0.92\right)$ and no significant interaction of time and neonatal condition $\left(F_{(2,19)}=1.54 ; p=0.24\right)$, indicating that there were no significant differences in the pharmacokinetics of morphine between the two neonatal conditions.

IL-10 mRNA expression within the NAcc is altered by neonatal handling and negatively correlates with the likelihood of drug-induced reinstatement of morphine CPP Together, the previous data indicate that neonatal handling programs the neuroimmune system toward an anti-inflammatory 

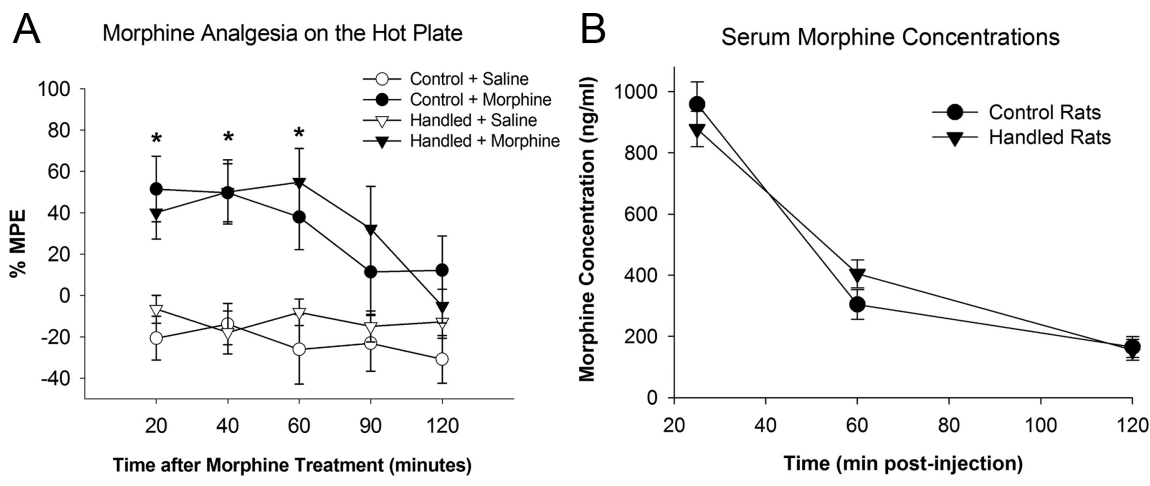

Figure 4. Neonatal handling does not affect analgesia produced by morphine or the pharmacokinetics of morphine when compared to nonhandled control rats in adulthood. A, Handled and nonhandled control rats were treated with $4 \mathrm{mg} / \mathrm{kg} \mathrm{morphine}$ ( $n=8 /$ group) subcutaneously, and the latency to respond on a hot plate $\left(52.5^{\circ} \mathrm{C}\right.$ ) was measured. Morphine significantly increases the latency to respond on the hot plate when compared to saline-treated control rats ${ }^{*} p<0.05$ compared to saline-treated groups ( $n=4 /$ group)] at the 20,40 , and 60 min time points. Analgesia was not affected by neonatal handling. $\boldsymbol{B}$, Serum morphine concentrations measured 25,60 , and $120 \mathrm{~min}$ following a subcutaneous dose of morphine $(4 \mathrm{mg} / \mathrm{kg})$ in handled and nonhandled control rats indicates that there are no significant effects of neonatal condition on the pharmacokinetic properties of morphine between the two groups.

A
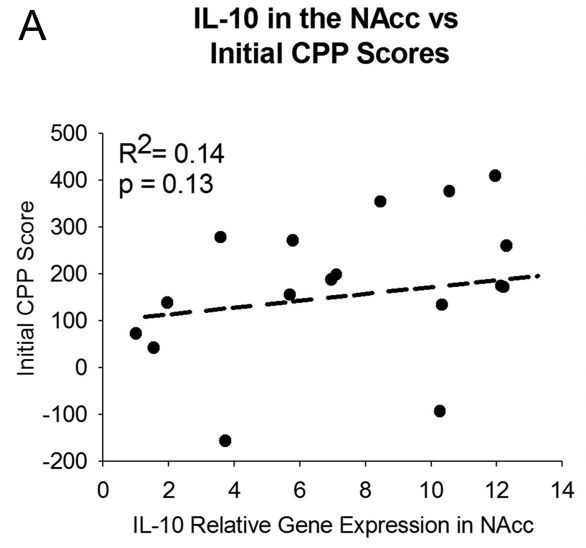
Initial CPP Scores
B

Figure 5. IL-10 mRNA expression within the NAcc does not correlate with initial CPP to morphine, but it does significantly correlate negatively with drug-induced reinstatement of morphine CPP in the same rats. $A, B$, From the rats used for CPP behavior in Figure 4, IL-10 mRNA was measured within the NAcc using real-time PCR and did not significantly correlate with previously measured morphine $C P P(A)$, yet it did negatively correlate with previously measured reinstatement of CPP following reexposure to $4 \mathrm{mg} / \mathrm{kg}$ morphine $(n=17$ animals total, 1 handled outlier; $p=0.02)(\boldsymbol{B})$.

bias via increased expression of IL-10 mRNA in the NAcc, prevents the glial activation and production of chemokines and cytokines to morphine (Fig. 1C), attenuates CPP to morphine (Fig. 3A), and blocks the subsequent reinstatement of morphine CPP following drug reexposure (Fig. $3 B$ ). To further explore these findings, baseline expression of IL-10 mRNA within the NAcc was assessed in handled and nonhandled control rats and correlated with previous morphine $\mathrm{CPP}$ and reinstatement behaviors (in the rats from Fig. $3 A, B$ ). IL-10 mRNA levels within the NAcc did not significantly correlate with initial CPP scores in the same rats $\left(R^{2}=0.14\right.$, $t_{15}=1.6, p=0.13$; Fig. $5 A$ ). However, we found a significant negative correlation between basal IL-10 expression within the NAcc and the reinstatement of morphine CPP precipitated by reexposure to $4 \mathrm{mg} / \mathrm{kg}$ morphine $\left(R^{2}=0.30, t_{15}=-2.55, p=\right.$ 0.02 ; Fig. $5 B$ ). These results suggest that elevated levels of the anti-inflammatory cytokine, IL-10, within the NAcc specifically decreases the likelihood of CPP reinstatement following drug reexposure. microglia.

\section{IL-10 expression within the NAcc is programmed early in development via glial-specific methylation of the $I L-10$ gene}

To explore the etiology of the difference in baseline IL-10 expression within the NAcc (Fig. 6A), a subset of pup brains was collected at P10 during the neonatal handling paradigm. IL-10 expression within the NAcc was already 3-fold greater in handled pups than in nonhandled control pups at this time point $\left(t_{14}=2.32, p=\right.$ 0.03 ; Fig. $6 B$ ), indicating that the difference in IL-10 expression is programmed early in development and maintained into adulthood.

To determine a putative mechanism of this long-term change in IL-10 expression, we analyzed relative methylation of a CpG island on the $I L-10$ gene (Fig. 6C) by using a methylated DNA immunoprecipitation assay, MeDIP. DNA methylation is a stable, long-term epigenetic change that is predominantly established early in development as cells are dividing and differentiating and thus is a likely candidate for the stable, long-term changes in IL-10 mRNA expression measured in the NAcc of neonatally handled rats. We initially found no significant differences in $I L-10$ gene methylation measured in whole NAcc tissues collected from each group $\left(t_{17}=-0.02, p=0.98\right.$; Fig. $\left.6 D\right)$. However, DNA methylation is a critical process of cellular differentiation, and thus the relative methylation levels, particularly of a cytokine gene such as IL-10, may be significantly different between neurons, glia, and/or microglia (Okano et al., 1999; Bogdanović and Veenstra, 2009). Neurons are not the primary producers of IL10 , and as such this gene may be silenced (highly methylated) in neurons, while methylation levels would remain relatively lower in cell types that produce IL-10, such as microglia (the primary immunocompetent cells in the brain). As a result, immunoprecipitation of methylated $I L-10$ from neurons would be overrepresented in an assay of whole tissue, potentially masking any differences in $I L-10$ gene methylation in microglia. Thus, we analyzed relative methylation levels of the $I L-10$ gene specifically in microglia rapidly isolated from NAcc tissue and detected a nearly a 5 -fold decrease in relative methylation of the $I L$ - 10 gene in handled rats when compared to nonhandled control rats $\left(t_{13}=\right.$ $-2.48, p=0.020$; Fig. $6 E$ ), indicating that the early-life epigenetic programming of IL-10 expression occurs specifically within

Systemic treatment with the glial modulator, ibudilast, increases IL-10 expression within the NAcc and blocks morphine-induced glial activation

To determine whether pharmacological manipulation of glia in adulthood could mimic the effects of neonatal handling, nonhandled control rats were treated systemically with ibudilast, a 
well known glial modulator, or its vehicle $30 \mathrm{~min}$ before morphine or saline administration, and the NAcc was collected for the analysis of cytokine and chemokine expression. Systemic ibudilast treatment significantly blocked all 10 of the inflammatory genes that were upregulated within the NAcc following morphine administration (Fig. 7; one-way ANOVA, $p<0.005$ for all genes depicted). Importantly, ibudilast alone increased the expression of IL-10 mRNA nearly 40-fold within the NAcc. These data indicate that, similar to the neonatal handling paradigm, ibudilast can shift glia into a predominantly antiinflammatory state, thus blocking morphine-induced glial activation without globally inhibiting glial function. Notably, ibudilast did not block the effects of morphine on CX3CL1/fractalkine (the neuronal cytokine), indicating the selectivity of this drug to glia.

\section{Ibudilast blocks drug-induced reinstatement of morphine CPP following morphine reexposure} Thus far, we have determined that neonatal handling and, similarly, systemic ibudilast treatment can shift glial function into a predominantly anti-inflammatory state via increased IL-10 expression within the NAcc and inhibit the rapid glial activation caused by morphine within the NAcc. We have also determined that IL-10 mRNA expression within the NAcc negatively correlates with increased risk of drug-induced reinstatement of CPP. Thus we sought to determine whether we could definitively block the reinstatement of morphine CPP in nonhandled control rats by inhibiting morphine-induced glial activation at the time of CPP by using ibudilast. Neonatally handled rats were also used in this paradigm for comparison. We predicted that ibudilast would have no further effects on the reinstatement of morphine CPP in handled rats.

Handled and nonhandled control rats were conditioned to morphine as described previously. Thirty minutes before morphine conditioning on each day, half of the rats in each group received a systemic injection with the glial modulator, ibudilast, or its vehicle. A two-way ANOVA for early-life experience $\times$ glial modulation indicated a significant main effect of early-life experience on morphine $\operatorname{CPP}\left(F_{(1,46)}=9.55 ; p=0.003\right.$; Fig. $\left.8 A\right)$. There was no significant main effect of systemic ibudilast treatment $\left(F_{(1,46)}=0.10 ; p=0.752\right)$ and no significant interaction between early-life experience and systemic ibudilast treatment $\left(F_{(1,46)}=0.18 ; p=0.670\right)$. Thus, neonatal handling significantly attenuated the rewarding preference to morphine, as before, whereas ibudilast had no effect on morphine CPP. In a control experiment, two groups of nonhandled control rats were conditioned to ibudilast $(7.5 \mathrm{mg} / \mathrm{kg}$, i.p.) or its vehicle using the CPP paradigm. We determined that systemic ibudilast treatment alone produced no significant reward or aversion (CPP score $=$
Baseline IL-10 mRNA in NAcc Postnatal Day 60

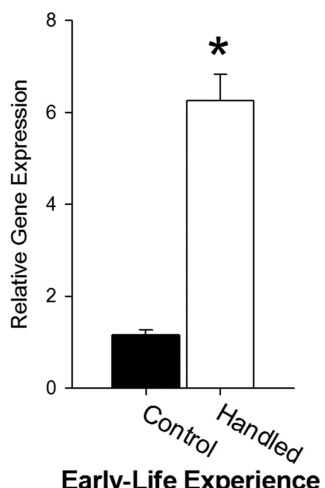

Early-Life Experience
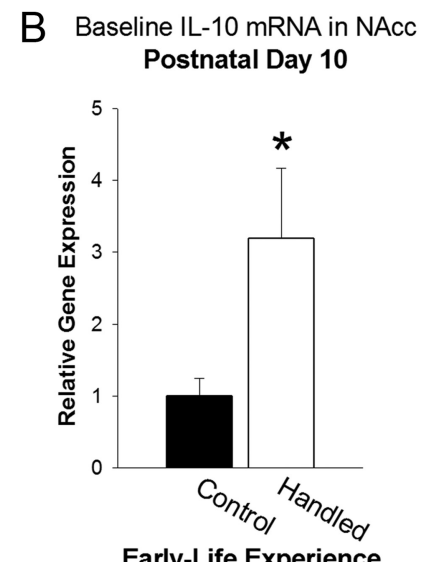

Early-Life Experience

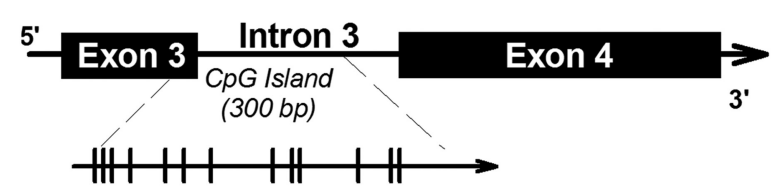

E Relative Methylated IL-10

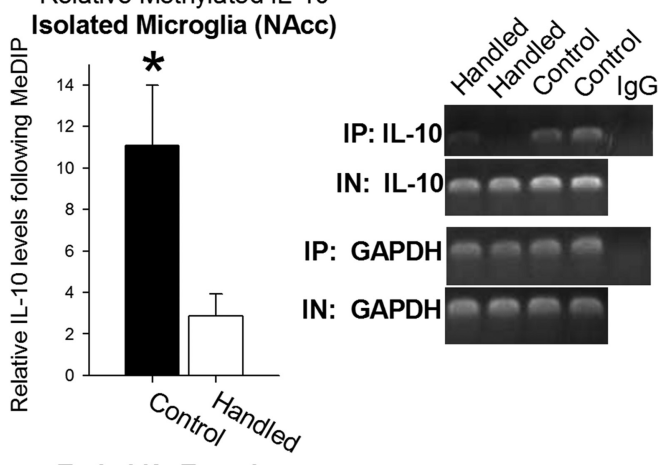

Early-LIfe Experience

Figure 6. IL-10 expression specifically within the NAcc can be programmed early in development via decreased methylation of the IL-10 gene. $\boldsymbol{A}$, Represented separately in graphical form from Figure 2, IL-10 mRNA was significantly upregulated nearly 4-fold in handled rats when compared to nonhandled control rats in the absence of morphine treatment. $\boldsymbol{B}$, Neonatal handling $(n=7)$ inceases the expression of IL-10 within the NAcc when compared to nonhandled controls $(n=8)$ by postnatal day 10 line). Primers for detection of $I L-10$ in immunoprecipitated and input samples were designed within this region. $D, E$, Neonatal handling had no effect on relative methylation levels measured within whole tissue dissections of the NAcc using MeDIP assay (handled: $n=10$; control: $n=9$ ) $(\boldsymbol{D}$ ), yet a significant decrease in relative methylation levels was measured in microglial cells isolated from the NAcc of handled rats ( $\left.{ }^{*} p<0.05\right)$, while having no effect on total $I L-10$ gene levels in input samples $(\boldsymbol{E})$.

$66.3 \pm 83 \mathrm{~s})$ in this paradigm when compared to its vehicle (CPP score $=87.3 \pm 50 \mathrm{~s} ; t_{8}=0.19, p=0.85$, data not shown $)$.

To assess the effects of ibudilast on drug-induced reinstatement of morphine CPP, all rats began an extinction phase immediately after CPP whereby they were placed into the CPP environment in the absence of morphine for a 5 min session, 3 times per week, and tested for morphine CPP (20 min test) once a week for 4 weeks. Data collected from these tests were analyzed using a repeated-measures ANOVA with test day, early-life experience, and glial modulation during $\mathrm{CPP}$ as factors, which revealed a significant main effect of test day $\left(F_{(4,164)}=8.05 ; p<\right.$ $0.0001)$, as all groups spent less time in the morphine-paired chamber upon repeated testing over the course of the month. The repeated-measures ANOVA also revealed a significant interaction of early-life experience and previous glial modulation on the rate of extinction $\left(F_{(4,164)}=3.29 ; p=0.013\right.$, data not shown), indicating that there was a significant difference in the rate of extinction that was differentially affected by neonatal handling 

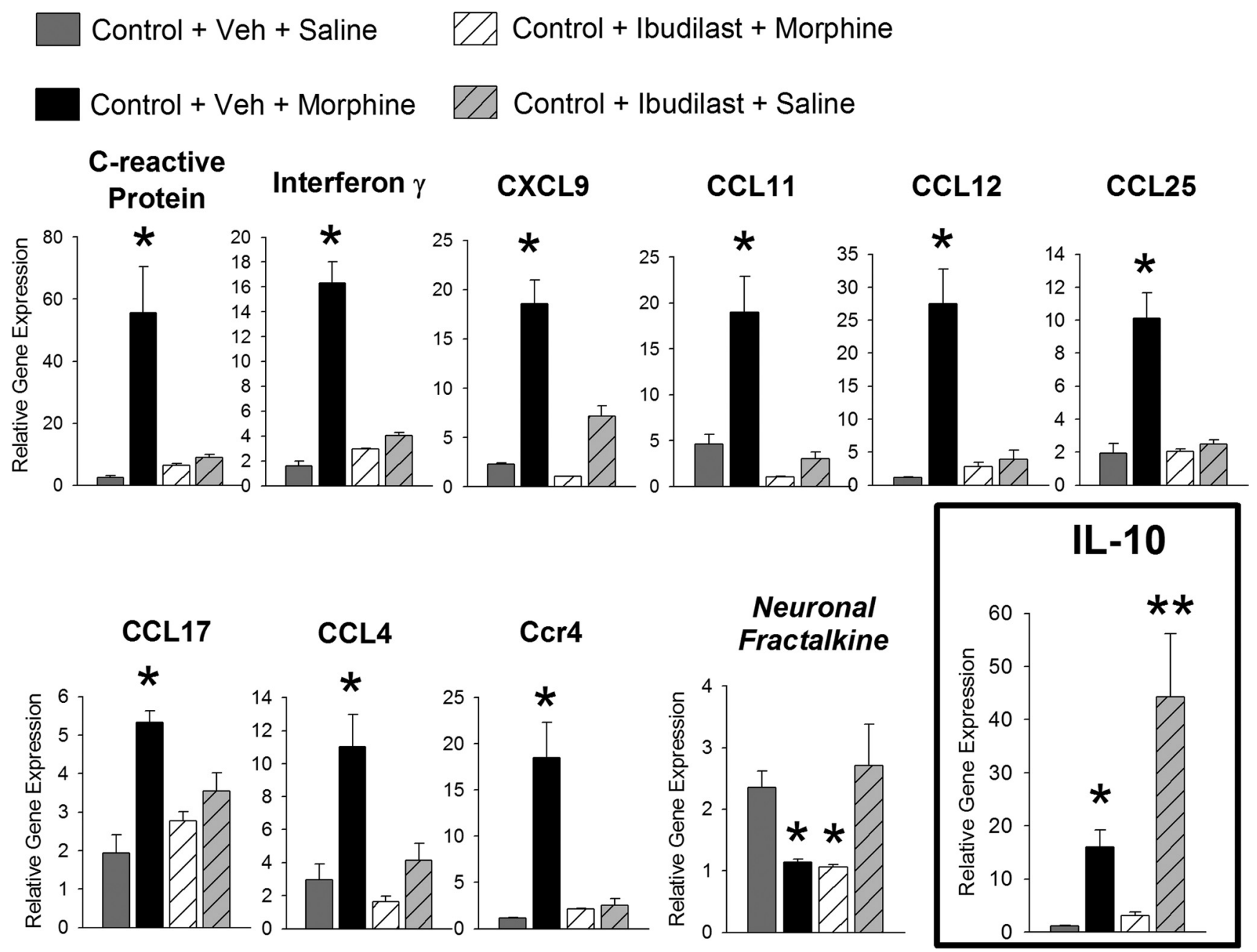

Figure 7. The glial modulator, ibudilast, significantly attenuates morphine-induced proinflammatory gene expression. Pretreatment with the glial inhibitor, ibudilast, 30 min before morphine administration significantly attenuates the morphine-induced expression of all 10 cytokines and chemokines within the NAcc. Ibudilast did not block the morphine-induced decrease in CX3CL1 mRNA (neuronal fractalkine), indicating it's specificity to glia. Ibudilast independently increases the expression of IL-10 nearly 40 -fold when compared to levels measured from vehicle (Veh)-treated, nonhandled control rats ( ${ }^{*}$ and ${ }^{* *}$ indicate $p<0.05$ from all other groups).

and gilal modulation that had occurred at the time of CPP. Specifically, neonatally handled rats and nonhandled control rats treated with ibudilast at the time of CPP showed a faster rate of extinction than nonhandled control rats treated with vehicle alone. After 4 weeks, all treatment groups spent significantly less time in the morphine-paired chamber than at the time of CPP, indicating that the CPP had been extinguished.

Using the same rats, we next tested the reinstatement of CPP following reexposure to morphine $\sim 8$ weeks after morphine CPP. As expected, saline treatment did not reinstate morphineseeking behavior (Fig. $8 \mathrm{~B}$ ). The next day, rats were treated with a priming dose of morphine $(2 \mathrm{mg} / \mathrm{kg}$ ) before being placed into the $\mathrm{CPP}$ environment, and data were analyzed using a two-way ANOVA for early-life experience $\times$ previous glial modulation. Analysis indicated a significant interaction of early-life experience $\times$ previous glial modulation (Fig. $8 B ; F_{(4,46)}=4.87 ; p=$ $0.03)$. Specifically, only nonhandled control rats reinstated the behavior after a priming dose of morphine when compared to neonatally handled rats $(p=0.012)$. Systemic treatment with ibudilast at the time of conditioning, months earlier, completely blocked the reinstatement of morphine-seeking behavior in nonhandled control rats when compared to vehicle-treated non- handled control rats $(p=0.004)$. We found the same effects on the reinstatement of drug-seeking behavior following $4 \mathrm{mg} / \mathrm{kg}$ morphine (significant interaction of early-life experience and previous glial modulation: $F_{(4,46)}=3.99 ; p=0.045$; Fig. $8 C$ ), this time 9 weeks after initial CPP, suggesting the effect of morphineinduced glial activation on drug-induced reinstatement of morphine CPP is very long-lasting.

In a separate control experiment, ibudilast given systemically (7.5 mg/kg, i.p.) in isolation 8 weeks before morphine CPP did not significantly affect morphine CPP 8 weeks later (CPP score $=$ $266.7 \pm 57 \mathrm{~s}$ ) when compared to rats given systemic ibudilast treatment at the time of morphine $\mathrm{CPP}(\mathrm{CPP}$ score $=199.9 \pm 48$; $t_{12}=-0.15, p=0.59$ ), suggesting that systemic treatment with ibudilast does not affect the long-term rewarding or associative properties of morphine.

Glial activation specifically within the NAcc is necessary for drug-induced reinstatement of morphine CPP in control rats Our evidence thus far suggests that the activation of microglia specifically within the NAcc may be a critical component for modulating the relative risk of drug-induced reinstatement to morphine CPP. To determine whether glial activation specifically 
within the NAcc is necessary for the expression of drug-induced reinstatement, nonhandled control rats were implanted with a bilateral cannula aimed at the NAcc for infusion with ibudilast. To determine an effective dose of ibudilast within the brain, we assessed expression levels of CD11b and GFAP mRNA, two well established markers of microglia and astrocyte activation, respectively, within the NAcc of nonhandled control rats infused with either vehicle or ibudilast ( 23 or $230 \mathrm{ng}$ ) $1 \mathrm{~h}$ before saline or morphine treatment. We determined that $230 \mathrm{ng}$ of ibudilast infused into the NAcc could sufficiently block the activation of both microglia (CD11b: $\left.F_{(3,15)}=3.16 ; p \leq 0.05\right)$ and astrocytes (GFAP: $F_{(3,15)}=3.3 ; p=0.049$ ) caused by morphine, while $23 \mathrm{ng}$ of ibudilast did not (Fig. 9A). We did find a significant overall increase in both CD11b and GFAP expression within the NAcc due to cannulation when these samples were compared to samples from uncannulated brains treated with or without morphine. However, this effect of cannulation did not preclude the increase in glial activation following morphine treatment and, interestingly, was not reduced by ibudilast treatment at either dose, suggesting that this was nonspecific, on-going activation of glia within the NAcc (data not shown).

In a separate cohort, rats were infused with either vehicle or $230 \mathrm{ng}$ of ibudilast $1 \mathrm{~h}$ before morphine conditioning (Fig. 9B). As seen previously with the systemic treatment, infusion of ibudilast into the NAcc did not significantly affect the initial CPP to morphine in control rats $\left(t_{21}=-0.12 ; p=0.90 ;\right.$ Fig. $\left.9 C\right)$, as both treatment groups found morphine similarly rewarding. Following extinction, both groups of rats showed no reinstatement of CPP following a noncontingent dose of saline. After a priming dose of morphine, control rats infused with the vehicle at the time of morphine CPP showed strong reinstatement to morphine $\mathrm{CPP}$, while rats infused with ibudilast at the time of CPP did not reinstate CPP following a priming dose of morphine $\left(t_{17}=2.4\right.$; $p=0.028$; Fig. $9 C$ ). These data suggest that morphine-induced activation of microglia specifically within the NAcc is necessary for the drug-induced reinstatement of morphine CPP in control rats.

\section{Discussion}

We report that morphine activates glia within the NAcc, rapidly upregulating the expression of cytokines and chemokine,; and this glial response is necessary for drug-induced reinstatement of morphine CPP months after the initial conditioning. We demonstrate that early-life experience produces an enduring antiinflammatory shift in this glial response via an epigenetic modification of a cytokine gene specifically within microglia. This change in IL-10 expression may attenuate the morphineinduced glial response and thus block drug-induced reinstatement of morphine CPP in adulthood. In support of these findings, we also determined that pretreatment of adult control rats with a well known glial modulator, ibudilast, increases IL-10 mRNA expression within the NAcc, blocks morphine-induced
B

C

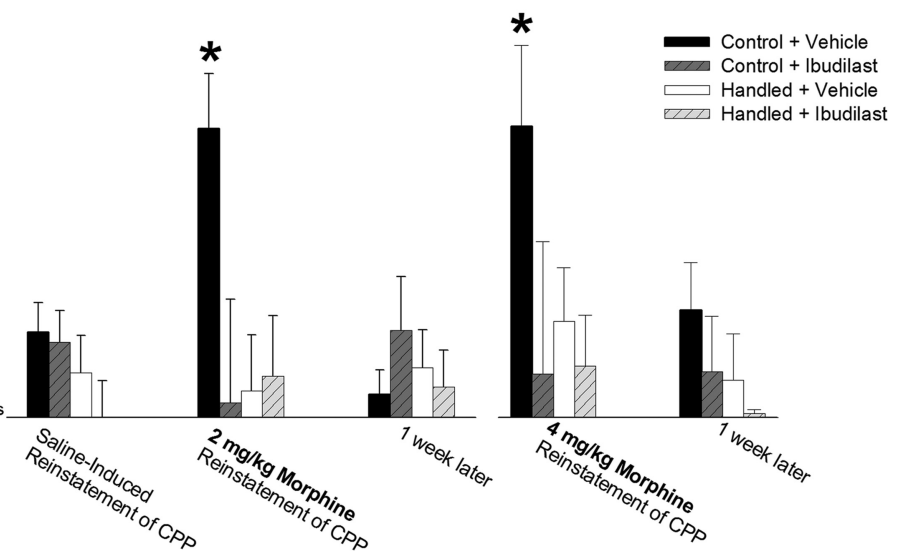

Figure 8. Ibudilast does not affect initial morphine CPP but mimics neonatal handling by significantly blocking drug-induced reinstatement of morphine (PP following either a priming dose $(2 \mathrm{mg} / \mathrm{kg}$ ) or a larger dose of morphine (4 mg/kg) in nonhandled ( glial activation at the time of CPP and neonatal handling were each sufficient to block the drug-induced reinstatement of morphine-seeking behavior ( ${ }^{*} p<0.05$ compared to all other groups).

glial activation, and prevents the drug-induced reinstatement of morphine CPP. Thus, our data support a novel hypothesis that morphine-induced glial activation within the NAcc at the time of morphine CPP can profoundly affect drug-induced reinstatement of CPP to morphine, and these outcomes are markedly affected by early-life programming of glial function.

\section{Neonatal handling programs IL-10 expression via decreased methylation of the IL-10 gene specifically within microglia} Neonatal handling is a well known manipulation for increasing maternal care during postnatal development, and this early-life experience has long-term beneficial consequences for the physiology and behavior of an animal. We demonstrate that neonatal handling programs the immune system within the brain toward an anti-inflammatory bias and increases the expression of the anti-inflammatory cytokine, IL-10, nearly 4 -fold compared to controls. IL-10 represses the expression of proinflammatory cytokines during the recovery phase of an immune response and is important for maintaining homeostasis within the periphery and CNS. The baseline difference in IL-10 expression between handled and nonhandled control rats was established early in development, by P10, during the course of neonatal handling. Methylation levels of the $I L-10$ gene specifically within microglia were nearly 5 -fold lower in handled rats than in nonhandled control rats, which may account for the significant life-long increase in baseline IL-10 expression within the brain. DNA methylation is a stable, long-term epigenetic modification that can be established or modified during the process of cell division and differentiation (e.g., during early brain development). Thus, it is not surprising that developmental changes to the epigenome resulting from increased maternal care that affect adult behaviors are a well documented phenomenon (Seckl and Meaney, 2004; Weaver et al., 2004; Champagne et al., 2003, 2006, 2008). How- 

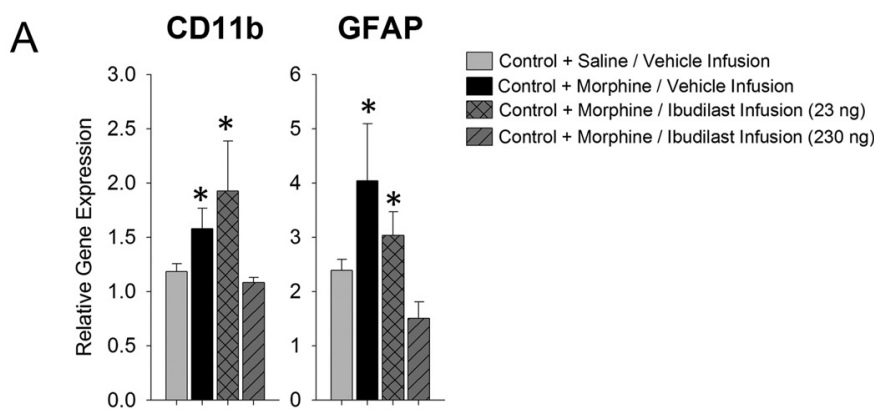

$\square$ Control + Morphine / Ibudilast Infusion (230 ng)

\section{B Ibudilast Vehicle}

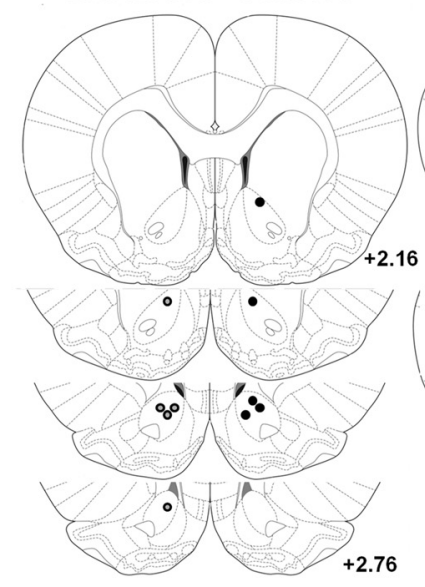

Ibudilast Vehicle

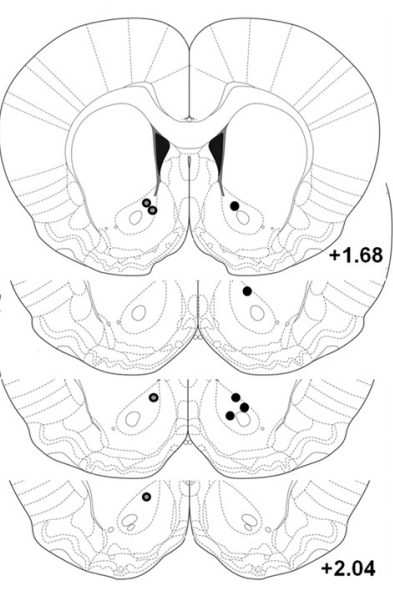

C

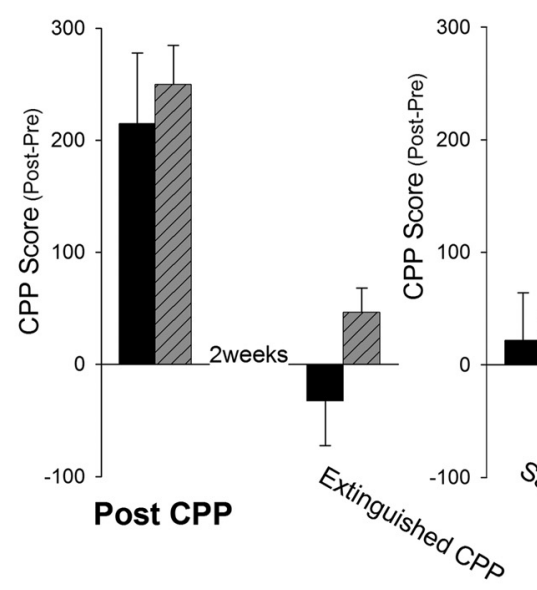

Control + Vehicle Infusion

$\square$ Control + Ibudilast Infusion (230 ng)

Figure 9. Infusion of ibudilast directly into the NAcc blocks the drug-induced reinstatement of morphine CPP in control rats. A, Nonhandled control rats were implanted with bilateral cannulae into the NAcc and infused with either vehicle or ibudilast (23 or $230 \mathrm{ng}) 1 \mathrm{~h}$ before morphine $(4 \mathrm{mg} / \mathrm{kg}$ ) administration. Gene expression of CD11b and GFAP indicate that morphine increases the expression of CD11b and GFAP, and infusion with ibudilast at a dose of $230 \mathrm{ng}$ was sufficient to block the increase in glial activation caused by systemic morphine treatment $\left({ }^{*} p<0.05\right.$ compared to other treatment groups). $\boldsymbol{B}$, Atlas depiction of cannulae placement for behavioral experiments. Left hemisphere depicts the placement of the cannulae in nonhandled control rats infused with 230 ng of ibudilast (gray dots), and the right hemisphere depicts the placement of the cannulae in nonhandled control rats infused with vehicle (black dots). All atlas references are from bregma according to Paxinos and Watson (2005). C, Infusion of ibudilast (230 ng) directly into the NAcc had no effect on morphine CPP. Following extinction, all rats showed no preference for the morphine-paired chamber. One week later, in the same rats injection with saline $(1 \mathrm{ml} / \mathrm{kg})$ alone does not reinstate morphine-seeking behavior in any of the rats; however, treatment of rats with a priming dose of morphine $(2 \mathrm{mg} / \mathrm{kg})$ was sufficient to reinstate morphine-seeking behavior in nonhandled controls rats, and this effect was blocked by previous infusion of $230 \mathrm{ng}$ of ibudilast into the NAcc $\left({ }^{*} p<\right.$ 0.05 control rats infused with ibudilast).

ever, our data provide the first evidence to our knowledge of a CNS cell-type-specific epigenetic change in gene expression that significantly affects glial function and correlates with behavior.

Attenuating morphine-induced glial activation with ibudilast attenuates drug-induced reinstatement of morphine CPP independent of initial reward

Previous research has shown that attenuating proinflammatory glial responses using the pharmacological modulators minocycline or propentofylline can completely block morphine CPP (Narita et al., 2006; Hutchinson et al., 2008b). Thus, we initially predicted that decreased glial activation produced by neonatal handling or ibudilast would attenuate morphine CPP to similar levels and were surprised to find that ibudilast did not mimic the effect of neonatal handling on morphine CPP. There are at least two potential explanations for these findings. First, increased maternal care increases baseline dopaminergic tone within the NAcc, attenuating dopamine release to sucrose, drugs, or stress and may thereby potentially lower the hedonic impact of such stimuli (Brake et al., 2004; Pruessner et al., 2004; Moffett et al., 2007). Second, cytokines from peripheral leukocytes that infiltrate the brain could also regulate aspects of morphine reward in handled rats. We determined that IL-10 protein was significantly increased in serum following morphine treatment in both groups, although significantly less so in handled rats, consistent with the literature indicating that morphine is immunosuppressive within the periphery (Budd, 2006; Sacerdote, 2008). We suspect that the differential glial response within the NAcc may be driving the differential peripheral immunosuppressive response between these groups and, consistent with this idea, others have reported that the NAcc is necessary for the peripheral immunosuppression induced by morphine (Saurer et al., 2008, 2009). Nonetheless, the contribution of peripheral immune cells to morphine reward and relapse and their modulation by early-life experience cannot be completely ruled out. In either case, glial activation is likely not the exclusive underlying mechanism by which attenuated reward is established in handled rats.

Glial activation within the NAcc is required for the reinstatement of morphine CPP following reexposure to a priming dose of morphine given months later

We have instead identified a critical and important role for morphine-induced glial activation in drug-induced reinstatement of drug-seeking behavior. We show that glial activation occurs during the association between morphine and the CPP environment. While our data suggest this glial response does not 
alter the immediate rewarding effects of the drug, it is necessary for drug-induced reinstatement of drug-seeking behavior months later. These findings support a growing literature suggesting that the neural mechanisms underlying the acute initial rewarding effects of drugs are different from those underlying drug seeking after abstinence/withdrawal from the drug (Shalev et al., 2002; Shaham et al., 2003; Kalivas and Volkow, 2005). Moreover, there is increasing support for a role of glia in addiction (Haydon et al., 2009; Miguel-Hidalgo, 2009; Ghitza et al., 2010). We hypothesize that the chemokines and cytokines that are rapidly upregulated within the NAcc following morphine exposure act as neuromodulators to alter neuronal activation, synaptic transmission, and synaptic connectivity, a distinct function from the traditionally defined role for cytokines and chemokines within the brain following infection or injury. Cytokines and chemokines, as well as their receptors, have been identified on many cell types including microglia and astrocytes (Nitta, 1998; Dorf et al., 2000; Croitoru-Lamoury et al., 2003); and in 2005 it was postulated that chemokines act as neuromodulators (Adler and Rogers, 2005).

We determined that CX3CL1, a cytokine produced in neurons that attenuates glial function, is downregulated following morphine administration, and this effect was not blocked by ibudilast pretreatment. This suggests that as neurons within the NAcc respond (likely to dopamine release), they downregulate CX3CL1 expression and release, thereby activating glia and stimulating the production of other cytokines and chemokines that may in turn affect synaptic function. We also demonstrate that CXCL9, a chemokine produced in response to interferon- $\gamma$, is upregulated nearly 15 -fold following morphine administration, and this chemokine has a demonstrated role as a neurotrophic factor (Gonzalez-Perez et al., 2010; Müller et al., 2010). A more recent literature is emerging that indicates that classical immune factors can also modulate the release of neurotransmitters, in particular DA within the striatum (Bezzi et al., 2001; Nicolai et al., 2010; Rostène et al., 2011; Santello et al., 2011). Ibudilast can attenuate DA release from NAcc neurons during an extended dosing paradigm of physical morphine dependence/withdrawal (Bland et al., 2009). We found that ibudilast does not attenuate morphine $\mathrm{CPP}$, suggesting that ibudilast does not attenuate the increase in DA produced by two daily doses of morphine and therefore cannot explain the lack of reinstatement weeks later; however these data do not discount the potential role of immune molecules in synaptic plasticity underlying motivation, reward, and reinstatement. Thus, our understanding of these immune molecules in a "noninjury" model requires further exploration. Our data suggest that the rapid glial response to morphine specifically within the NAcc may induce long-term changes in the greater circuit underlying drug-induced reinstatement of CPP, and our future research will seek to identify the specific mechanisms of these cytokines/chemokines in this model.

Handled rats did not reinstate drug-seeking behavior after reexposure to morphine in these experiments. While this may be due to the fact that handled rats found morphine less rewarding initially, the significant negative correlation between IL-10 mRNA expression within the NAcc and reinstatement of CPP behavior suggests otherwise. We propose instead that because handled rats have a profoundly attenuated inflammatory response to morphine within the NAcc as a result of differential IL-10 transcription, they are protected from the long-term changes in neurocircuitry that occur as a result of glial activation and affect subsequent drug-induced reinstatement of CPP despite initial attenuated reward.
In closing, relapse to drug abuse following long periods of abstinence remains one of the most difficult challenges in the treatment of drug addiction in humans (O'Brien, 1997). Only a small percentage of the human population succumbs to addiction after exposure to drugs of abuse, yet the toll on society is great. The handling manipulation used here likely represents the "typical" human response to drugs of abuse, whereas nonhandled "controls" represent the minority at increased risk for addiction. We have identified a novel role for the neuroimmune system in reinstatement of morphine CPP following drug reexposure. Our data suggest that potential drug-induced reinstatement of CPP can be programmed by early-life experience via epigenetic changes to microglia or manipulated by adult interventions that also target glia. Ibudilast is currently used for the treatment of asthma and other inflammatory conditions of the CNS and is well tolerated when given systemically in humans (Rolan et al., 2009); thus, further research identifying the potential use of ibudilast as a drug addiction treatment is warranted. Moreover, future research that focuses on the interaction of early-life environment and genes associated with the immune response may be a critical next step in identifying at-risk individuals and potential treatment therapies targeting glia.

\section{References}

Adler MW, Rogers TJ (2005) Are chemokines the third major system in the brain? J Leukoc Biol 78:1204-1209.

Bezzi P, Domercq M, Brambilla L, Galli R, Schols D, De Clercq E, Vescovi A, Bagetta G, Kollias G, Meldolesi J, Volterra A (2001) CXCR4-activated astrocyte glutamate release via TNFalpha: amplification by microglia triggers neurotoxicity. Nat Neurosci 4:702-710.

Bilbo SD, Newsum NJ, Sprunger DB, Watkins LR, Rudy JW, Maier SF (2007) Differential effects of neonatal handling on early life infection-induced alterations in cognition in adulthood. Brain Behav Immun 21:332-342.

Bland ST, Hutchinson MR, Maier SF, Watkins LR, Johnson KW (2009) The glial activation inhibitor AV411 reduces morphine-induced nucleus accumbens dopamine release. Brain Behav Immun 23:492-497.

Bland ST, Beckley JT, Watkins LR, Maier SF, Bilbo SD (2010) Neonatal Escherichia coli infection alters glial, cytokine, and neuronal gene expression in response to acute amphetamine in adolescent rats. Neurosci Lett 474:52-57.

Bogdanović O, Veenstra GJ (2009) DNA methylation and methyl-CpG binding proteins: Developmental requirements and function. Chromosoma 118:549-565.

Brake WG, Zhang TY, Diorio J, Meaney MJ, Gratton A (2004) Influence of early postnatal rearing conditions on mesocorticolimbic dopamine and behavioural responses to psychostimulants and stressors in adult rats. Eur J Neurosci 19:1863-1874.

Budd K (2006) Pain management: Is opioid immunosuppression a clinical problem? Biomed Pharmacother 60:310-317.

Campbell J, Spear LP (1999) Effects of early handling on amphetamineinduced locomotor activation and conditioned place preference in the adult rat. Psychopharmacology 143:183-189.

Champagne DL, Bagot RC, van Hasselt F, Ramakers G, Meaney MJ, de Kloet ER, Joëls M, Krugers H (2008) Maternal care and hippocampal plasticity: Evidence for experience-dependent structural plasticity, altered synaptic functioning, and differential responsiveness to glucocorticoids and stress. J Neurosci 28:6037-6045.

Champagne FA, Weaver IC, Diorio J, Sharma S, Meaney MJ (2003) Natural variations in maternal care are associated with estrogen receptor alpha expression and estrogen sensitivity in the medial preoptic area. Endocrinology 144:4720-4724.

Champagne FA, Weaver IC, Diorio J, Dymov S, Szyf M, Meaney MJ (2006) Maternal care associated with methylation of the estrogen receptoralphalb promoter and estrogen receptor-alpha expression in the medial preoptic area of female offspring. Endocrinology 147:2909-2915.

Croitoru-Lamoury J, Guillemin GJ, Boussin FD, Mognetti B, Gigout LI, Chéret A, Vaslin B, Le Grand R, Brew BJ, Dormont D (2003) Expression of chemokines and their receptors in human and simian astrocytes: evi- 
dence for a central role of TNF alpha and IFN gamma in CXCR4 and CCR5 modulation. Glia 41:354-370.

Cunningham CL, Gremel CM, Groblewski PA (2006) Drug-induced conditioned place preference and aversion in mice. Nat Protoc 1:1662-1670.

Dorf ME, Berman MA, Tanabe S, Heesen M, Luo Y (2000) Astrocytes express functional chemokine receptors. J Neuroimmunol 111:109-121.

Frank MG, Wieseler-Frank JL, Watkins LR, Maier SF (2006) Rapid isolation of highly enriched and quiescent microglia from adult rat hippocampus: immunophenotypic and functional characteristics. J Neurosci Methods 151:121-130.

Ghitza UE, Zhai H, Wu P, Airavaara M, Shaham Y, Lu L (2010) Role of $\mathrm{BDNF}$ and GDNF in drug reward and relapse: a review. Neurosci Biobehav Rev 35:157-171.

Gonzalez-Perez O, Jauregui-Huerta F, Galvez-Contreras AY (2010) Immune system modulates the function of adult neural stem cells. Curr Immunol Rev 6:167-173.

Haydon PG, Blendy J, Moss SJ, Rob Jackson F (2009) Astrocytic control of synaptic transmission and plasticity: a target for drugs of abuse? Neuropharmacology 56 [Suppl 1]:83-90.

Hutchinson MR, Coats BD, Lewis SS, Zhang Y, Sprunger DB, Rezvani N, Baker EM, Jekich BM, Wieseler JL, Somogyi AA, Martin D, Poole S, Judd CM, Maier SF, Watkins LR (2008a) Proinflammatory cytokines oppose opioidinduced acute and chronic analgesia. Brain Behav Immun 22:1178-1189.

Hutchinson MR, Northcutt AL, Chao LW, Kearney JJ, Zhang Y, Berkelhammer DL, Loram LC, Rozeske RR, Bland ST, Maier SF, Gleeson TT, Watkins LR (2008b) Minocycline suppresses morphine-induced respiratory depression, suppresses morphine-induced reward, and enhances systemic morphine-induced analgesia. Brain Behav Immun 22:1248-1256.

Hutchinson MR, Lewis SS, Coats BD, Skyba DA, Crysdale NY, Berkelhammer DL, Brzeski A, Northcutt A, Vietz CM, Judd CM, Maier SF, Watkins LR, Johnson KW (2009) Reduction of opioid withdrawal and potentiation of acute opioid analgesia by systemic AV411 (ibudilast). Brain Behav Immun 23:240-250.

Jaworski JN, Francis DD, Brommer CL, Morgan ET, Kuhar MJ (2005) Effects of early maternal separation on ethanol intake, GABA receptors and metabolizing enzymes in adult rats. Psychopharmacology 181:8-15.

Kalivas PW, Volkow ND (2005) The neural basis of addiction: A pathology of motivation and choice. Am J Psychiatry 162:1403-1413.

Kiebala M, Maggirwar SB (2011) Ibudilast, a pharmacologic phosphodiesterase inhibitor, prevents human immunodeficiency virus-1 Tat-mediated activation of microglial cells. PLoS One 6:e18633.

Kosten TA, Miserendino MJ, Kehoe P (2000) Enhanced acquisition of cocaine self-administration in adult rats with neonatal isolation stress experience. Brain Res 875:44-50.

Levine S (1967) Maternal and environmental influences on the adrenocortical response to stress in weanling rats. Science 156:258-260.

Lu L, Shepard JD, Hall FS, Shaham Y (2003) Effect of environmental stressors on opiate and psychostimulant reinforcement, reinstatement and discrimination in rats: a review. Neurosci Biobehav Rev 27:457-491.

Meaney MJ, Mitchell JB, Aitken DH, Bhatnagar S, Bodnoff SR, Iny LJ, Sarrieau A (1991) The effects of neonatal handling on the development of the adrenocortical response to stress: Implications for neuropathology and cognitive deficits in later life. Psychoneuroendocrinology 16:85-103.

Michaels CC, Holtzman SG (2008) Early postnatal stress alters place conditioning to both mu- and kappa-opioid agonists. J Pharmacol Exp Ther 325:313-318.

Miguel-Hidalgo JJ (2009) The role of glial cells in drug abuse. Curr Drug Abuse Rev 2:76-82.

Miller CA, Gavin CF, White JA, Parrish RR, Honasoge A, Yancey CR, Rivera IM, Rubio MD, Rumbaugh G, Sweatt JD (2010) Cortical DNA methylation maintains remote memory. Nat Neurosci 13:664-666.

Moffett MC, Vicentic A, Kozel M, Plotsky P, Francis DD, Kuhar MJ (2007) Maternal separation alters drug intake patterns in adulthood in rats. Biochem Pharmacol 73:321-330.

Müller M, Carter S, Hofer MJ, Campbell IL (2010) Review: The chemokine receptor CXCR3 and its ligands CXCL9, CXCL10 and CXCL11 in neuro- immunity-a tale of conflict and conundrum. Neuropathol Appl Neurobiol 36:368-387.

Narita M, Miyatake M, Narita M, Shibasaki M, Shindo K, Nakamura A, Kuzumaki N, Nagumo Y, Suzuki T (2006) Direct evidence of astrocytic modulation in the development of rewarding effects induced by drugs of abuse. Neuropsychopharmacology 31:2476-2488.

Narita M, Suzuki M, Kuzumaki N, Miyatake M, Suzuki T (2008) Implication of activated astrocytes in the development of drug dependence: Differences between methamphetamine and morphine. Ann N Y Acad Sci 1141:96-104.

Nicolai J, Burbassi S, Rubin J, Meucci O (2010) CXCL12 inhibits expression of the NMDA receptor's NR2B subunit through a histone deacetylasedependent pathway contributing to neuronal survival. Cell Death Dis 1:e33.

Nitta T (1998) Cytokine gene expression within the central nervous system. Cell Mol Neurobiol 18:703-708.

O’Brien CP (1997) A range of research-based pharmacotherapies for addiction. Science 278:66-70.

Okano M, Bell DW, Haber DA, Li E (1999) DNA methyltransferases Dnmt3a and Dnmt3b are essential for de novo methylation and mammalian development. Cell 99:247-257.

Paxinos G, Watson C (2005) The rat brain in stereotaxic coordinates. New York: Academic.

Pruessner JC, Champagne F, Meaney MJ, Dagher A (2004) Dopamine release in response to a psychological stress in humans and its relationship to early life maternal care: A positron emission tomography study using $\left[{ }^{11} \mathrm{C}\right]$ raclopride. J Neurosci 24:2825-2831.

Rolan P, Hutchinson M, Johnson K (2009) Ibudilast: a review of its pharmacology, efficacy and safety in respiratory and neurological disease. Expert Opin Pharmacother 10:2897-2904.

Rostène W, Dansereau MA, Godefroy D, Van Steenwinckel J, Reaux-Le Goazigo A, Mélik-Parsadaniantz S, Apartis E, Hunot S, Beaudet N, Sarret P (2011) Neurochemokines: A menage a trois providing new insights on the functions of chemokines in the central nervous system. J Neurochem 118:680-694.

Sacerdote P (2008) Opioid-induced immunosuppression. Curr Opin Support Palliat Care 2:14-18.

Santello M, Bezzi P, Volterra A (2011) TNFalpha controls glutamatergic gliotransmission in the hippocampal dentate gyrus. Neuron 69:988-1001.

Saurer TB, Ijames SG, Carrigan KA, Lysle DT (2008) Neuroimmune mechanisms of opioid-mediated conditioned immunomodulation. Brain Behav Immun 22:89-97.

Saurer TB, Ijames SG, Lysle DT (2009) Evidence for the nucleus accumbens as a neural substrate of heroin-induced immune alterations. J Pharmacol Exp Ther 329:1040-1047.

Seckl JR, Meaney MJ (2004) Glucocorticoid programming. Ann N Y Acad Sci 1032:63-84.

Shaham Y, Shalev U, Lu L, De Wit H, Stewart J (2003) The reinstatement model of drug relapse: History, methodology and major findings. Psychopharmacology 168:3-20.

Shalev U, Grimm JW, Shaham Y (2002) Neurobiology of relapse to heroin and cocaine seeking: A review. Pharmacol Rev 54:1-42.

Somogyi AA, Larsen M, Abadi RM, Jittiwutikarn J, Ali R, White JM (2008) Flexible dosing of tincture of opium in the management of opioid withdrawal: Pharmacokinetics and pharmacodynamics. Br J Clin Pharmacol 66:640-647.

Sternberg WF, Ridgway CG (2003) Effects of gestational stress and neonatal handling on pain, analgesia, and stress behavior of adult mice. Physiol Behav 78:375-383.

Suzumura A, Ito A, Yoshikawa M, Sawada M (1999) Ibudilast suppresses TNFalpha production by glial cells functioning mainly as type III phosphodiesterase inhibitor in the CNS. Brain Res 837:203-212.

Weaver IC, Diorio J, Seckl JR, Szyf M, Meaney MJ (2004) Early environmental regulation of hippocampal glucocorticoid receptor gene expression: Characterization of intracellular mediators and potential genomic target sites. Ann N Y Acad Sci 1024:182-212. 